\title{
AVALIAÇÃo DA BEBIDA E OUTRAS CARACTERISTICAS DE CULTIVARES DE COFFEA CANEPHORA E COFFEA CONGENSIS ( ${ }^{\prime}$ )
}

A. A. Teixeira, Instituto Brasileiro do Café, A. Carvalho e L. C. Fazuoli $\left({ }^{2}\right)$, Seção de Genética, Instituto Agronômico

\section{SNOPSE}

Analisaram-se várias características morfológicas de amostras de sementes e a qualidade do produto de alguns cultivares de Coffea canephora e de $\mathbf{C}$. congensis, coletades em quatro localidades do Estado de São Paulo. Utilizou-se uma escala de cinco pontos, desenvolvida em Angola, para avaliação da qualidade da bebida de C. canephora Os dados obtidos foram comparados com os dos padrōes kouillou de C. canephora do Estado do Espírito Santo e mundo-novo de C. arabica.

Verificou-se que $46 \%$ das amostras de sementes beneficiadas foram classificadas como pertencentes a $\mathbf{C}$. arabica e, $36 \%$, a C. canephora. As porcentagens de sementes do tipo moca variaram de 10 a $50 \%$ para as amostras de C. canephora e de 20 a $40 \%$ para C. congensis. Para o mundo-novo essa porcentagem foi de $15 \%$. Os dados referentes à qualidade da bebida indicaram que oito amostras deram bebida significativamente melhor do que a do padrāo kouillou e nenhuma se revelou melhor do que a do mundo-novo. Comparaçōes entre as médias de pontos conferidos à bebida de 17 amostras de C. canephora despolpadas com as correspondentes nāo despolpadas, revelaram diferenças significativas, indicando que a operação do despolpamento contribuiu para a melhoria da qualidade da bebida. As amostras de café despolpadas de C. canephora colhidas em Ribeirāo Preto revelaram-se de melhor qualidade de bebida, em relaçăo às das outras três localidades: Tietê, Jaú e Pindorama.

Os dados obtidos evidenciaram, ainda, que os cultivares de $C$. congensis e de C. canephora podem dar bebida de qualidade semelhante.

\section{INTRODUÇÃO}

Das duas espécies de café mais cultivadas, Coffea arabica, que produz o café comercialmente conhecido por arábica, e C. canephora, que dá o café robusta, a primeira reúne maior número de características valiosas,

(1) Trabalho parcialmente executado com auxílio do Instituto Brasileiro do Café. Um resumo foi apresentado à 29. a Reunião Anual da S.B.P.C. - Sāo Paulo (SP), de 6 a 13 de julho de 1977. Os autores agradecem a colaboração dos classificadores Sr. José Luís Barbosa de Toledo e Moacir Aprigio de Meneses, do IBC. Recebido para publicação em 24 de novembro de 1978.

(2) Com bolsa de suplementação do CNPq. 
Vol. 38, N. ${ }^{\circ} 5$

como aparência, uniformidade do tamanho das sementes, reduzida quantidade de grãos moca, película prateada clara e não aderente, torraçăo uniforme e bebida de melhor qualidade. Poucas informações existem sobre o café produzido por $\mathbf{C}$. congensis. C. canephora, com freqüência, apresenta sementes com maior variabilidade no tamanho, película aderente e de cor marrom e quantidade elevada de grãos moca. A bebida é considerada de qualidade menos aceitável, o que tem como reflexo as menores cotações do produto no comércio.

A mistura dessas duas espécies de café, arábica e robusta, vem sendo realizada para redução do preço do produto, principalmente no preparo do café solúvel, embora se saiba que - solúvel obtido apenas a partir de C. arabica apresenta bebida de melhor qualidade do que o resultante da mistura. Experimentos realizados com esses cafés (3) mostraram que a bebida preparada com uma mistura de grãos de $\mathbf{C}$. canephora e $\mathbf{C}$. arabica de bebida mole, na proporção de até $40 \%$ de C. canephora, não difere daquela preparada apenas com $\mathbf{C}$. arabica.

O Brasil, porém, não tem tradição no cultivo de C. canephora. Apenas em algumas regiões do Estado do Espírito Santo cultiva-se o café, ai conhecido por conilon (C. canephora cv. kouillou), o qual é vendido em mistura com o C. arabica ou diretamente para a indústria do solúvel. Atualmente, porém, vem aumentando o interesse pelo cultivo de C. canephora na região amazônica e, de maneira geral, em localidades de menor altitude e de elevada temperatura e umidade. Experimentos com diferentes cultivares de $\mathbf{C}$. canephora
C. congensis acham-se estabelecidos no planalto paulista, em regiöes tradicionalmente produtoras de C. arabica, a fim de verificar o desenvolvimento geral e poder apreciar o produto aí produzido.

No presente trabalho efetuaram-se observações em amostras dessas espécies de café colhidas no planalto de São Paulo e no litoral do Espírito Santo, a fim de se analisar a variabilidade de algumas características morfológicas das sementes e a qualidade do produto.

\section{MATERIAL E METODOS}

Prepararam-se 56 amostras de café beneficiado de, aproximadamente, 400 gramas cada uma, sendo 16 da localidade de Tietê, 6 de Jaú, 6 de Pindorama e 27 de Ribeirão Preto, Estado de São Paulo, e uma de Marilândia, Estado do Espírito Santo. Como padrão foi tomada a amostra de C. canephora cv. kouillou, coletada em Marilândia. Utilizou-se, também para comparações, café do cultivar mundo-novo de C. arabica, provindo de Pindorama. Em algumas amostras o café foi despolpado, lavado e posto a secar ao sol e, em outras, os frutos foram secos ao sol diretamente, em caixas de fundo de tela de arame, dando o café em coco. As amostras foram beneficiadas e catadas para eliminação dos defeitos, antes de serem torradas e submetidas aos testes de avaliação do aspecto e bebida. Escolheram-se as amostras, principalmente entre cafeeiros dos cultivares guarini, bukobensis e robusta, de C. canephora. Algumas das amostras são de cultivares de $\mathbf{C}$. congensis, conforme indicado no quadro 1 . 


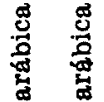

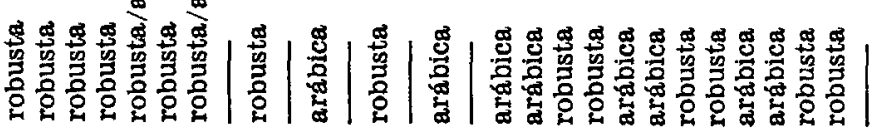

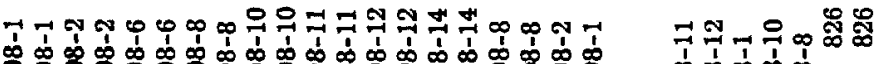

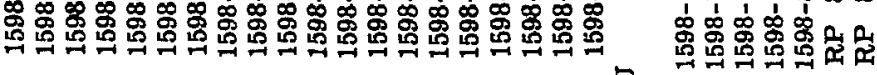

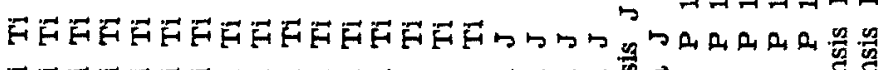

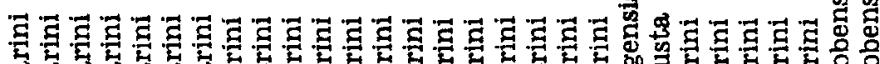

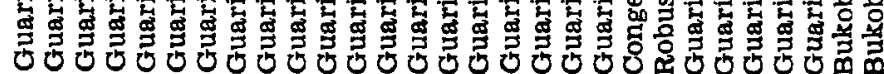




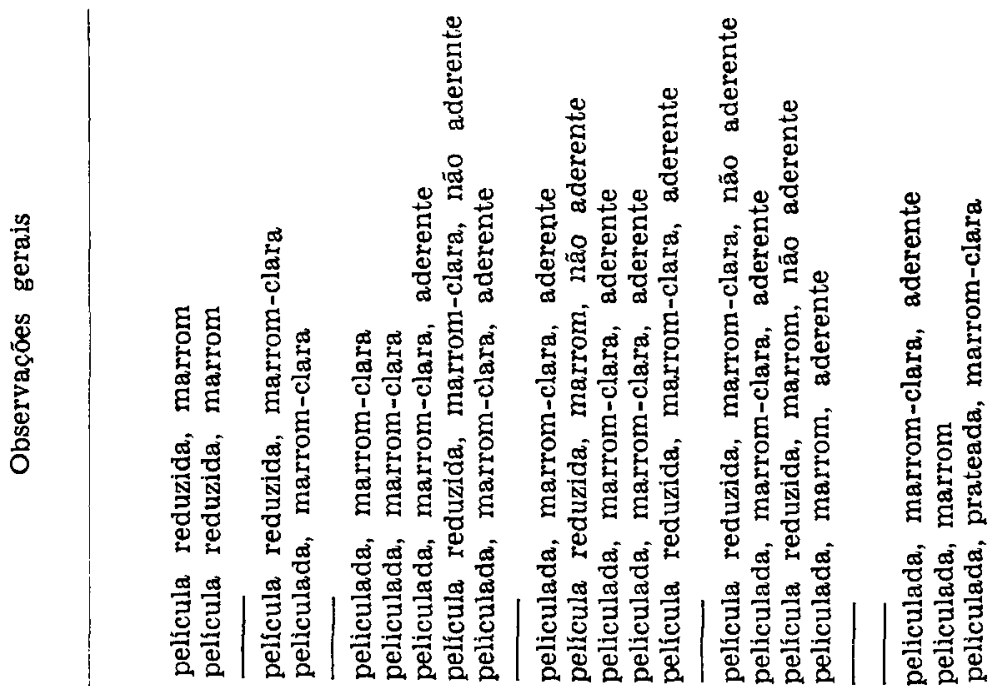

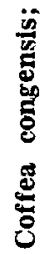

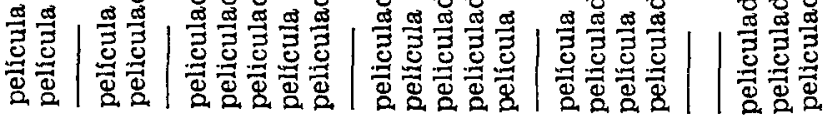

8

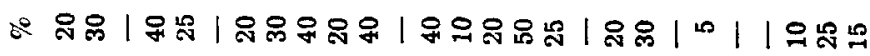

क 5 क

展

总

ค. เ્ّ

مै

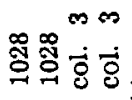

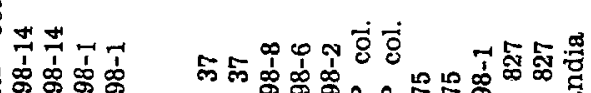

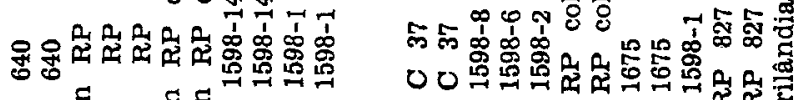

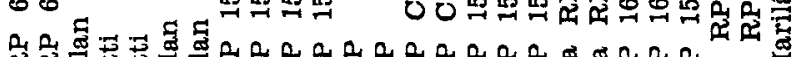

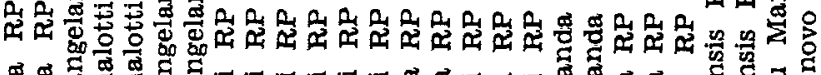

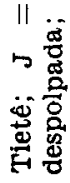

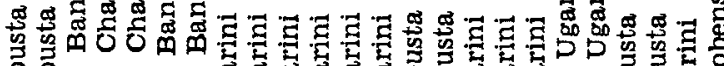
مे 
Utilizou-se o delineamento estatístico reticulado retangular $7 \times 8$, triplo, repetido três vezes, resultando em nove repetições. Para a prova de xícaras, as amostras foram preparadas de acordo com o que normalmente se faz para C. arabica (4). Em cada mesa de prova, distribuíram-se sete amostras, correspondentes a sete tratamentos do experimento, e uma de café padrão de bebida previamente conhecida. Para a avaliação da qualidade da bebida deram-se pontos de 1 a 5 , conforme utilizado para os cafés de Angola $(\mathbf{2}, \mathbf{7})$, sendo 1 ponto para a bebida excelente, com sabor neutro e alguma acidez; 2 pontos para a bebida muito boa, café com sabor neutro e ligeira acidez; 3 pontos para a bebida boa, café com leve para média gosto de robusta; 4 pontos para a bebida regular, café com forte gosto de robusta, e 5 pontos para a bebida má, café com gosto anormal (fermentado, de terra, de batata, mofado ou outros defeitos). Analisaram-se, também, algumas características morfológicas dos grãos verdes e calcularam-se as porcentagens de grãos do tipo moca, por amostra.

A avaliação da bebida foi realizada por dois técnicos, independentemente um do outro, e os resultados médios de seis determinações foram usados para a análise do experimento. Para comparações de média utilizou-se o teste de Tukey a 5\%. Empregou-se também esse teste para comparações com as testemunhas kouillou e mundo-novo, em virtude de não se poder aplicar o teste de Dunnett, por falta de tabela apropriada. Para comparações entre os tratamentos despolpados e não despolpados, usou-se o teste $\mathrm{F}$ a $1 \%$. Para fins de classificação dos tipos, os cafés dos cultivares de C. cane- phora foram denominados genericamente robusta, os de C. congensis, congensis, e, os de C. arabica, café arábica.

\section{RESULTADOS}

De 44 amostras examinadas do ponto de vista do aspecto morfológico, indicadas no quadro 1,16 foram classificadas como do tipo robusta, quatro como robusta/arábica, quatro como arábica/robusta e, vinte, tipo arábica. Das onze amostras coletadas em Tietê, sete deram grãos com aparência de robusta, duas de robusta/arábica e duas de arábica (18\%); das seis de Jaú, duas deram tipo robusta e quatro arábica (67\%); das cinco de Pindorama, três deram tipo robusta e duas arábica $(40 \%)$ e, das 20 de Ribeirão Preto, três foram classificadas como do tipo robusta, duas do tipo robusta/ arábica, quatro de arábica/robusta e onze do tipo arábica (55\%), indicando aspecto mais do tipo arábica e, portanto, mais favorável, dos cafés de Jaú e Ribeirão Preto. Das seis amostras de congensis analisadas, duas deram tipo robusta/arábica, duas tipo arábica/robusta e duas arábica, enquanto das 27 amostras do cultivar guarini, 14 são do tipo robusta, duas robusta/arábica, uma do arábica/robusta e dez do arábica. Todas as amostras de Tietê revelaram possuir película marrom; as de Jaú e Pindorama, marrom-clara e amarelada, enquanto 14 de Ribeirão Preto revelaram cor marrom-clara e, seis, marrom.

Das 30 amostras despolpadas, onze deram tipo robusta, três robusta/ 
arábica, uma arábica/robusta e quinze arábica $(50 \%)$. Das 14 amostras não despolpadas, cinco deram tipo robusta, uma robusta/arábica, três arábica/ robusta e cinco arábica (36\%). Das 30 despolpadas, 13 têm película marrom, 13 marrom-clara, duas amarelas e duas não tiveram a cor identificada e, das 14 não despolpadas, quatro deram película marrom, nove marrom-clara e, uma, não identificada.

Com relação à quantidade de grãos moca, o cultivar guarini deu valores que variaram de 10 a $50 \%$;
- robusta, de 5 a $30 \%$; os cultivares de C. congensis, de 20 a $40 \%$, enquanto a amostra de mundo-novo deu $15 \%$. Convém notar que as quantidades mais baixas foram observadas nas plantas 'guarini' 1598-8 de Jaú (10\%), 1598-12 de Pindorama (15\%), nas de 'robusta' RP C $37(10 \%)$ e $1675(5 \%)$ e nas de 'bukobensis' $826(10 \%)$ e 827 (10\%), de Ribeirão Preto.

Os dados médios obtidos para a classificação da bebida acham-se no quadro 2 .

QUADRO 2. - Valores méđios atribuídos à qualidade da bebida dos cafés robusta e congensis, despolpados ou nāo, de várias procedências, em comparação com os padrōes kouillou de C. canephora e mundo-novo de C. arabica

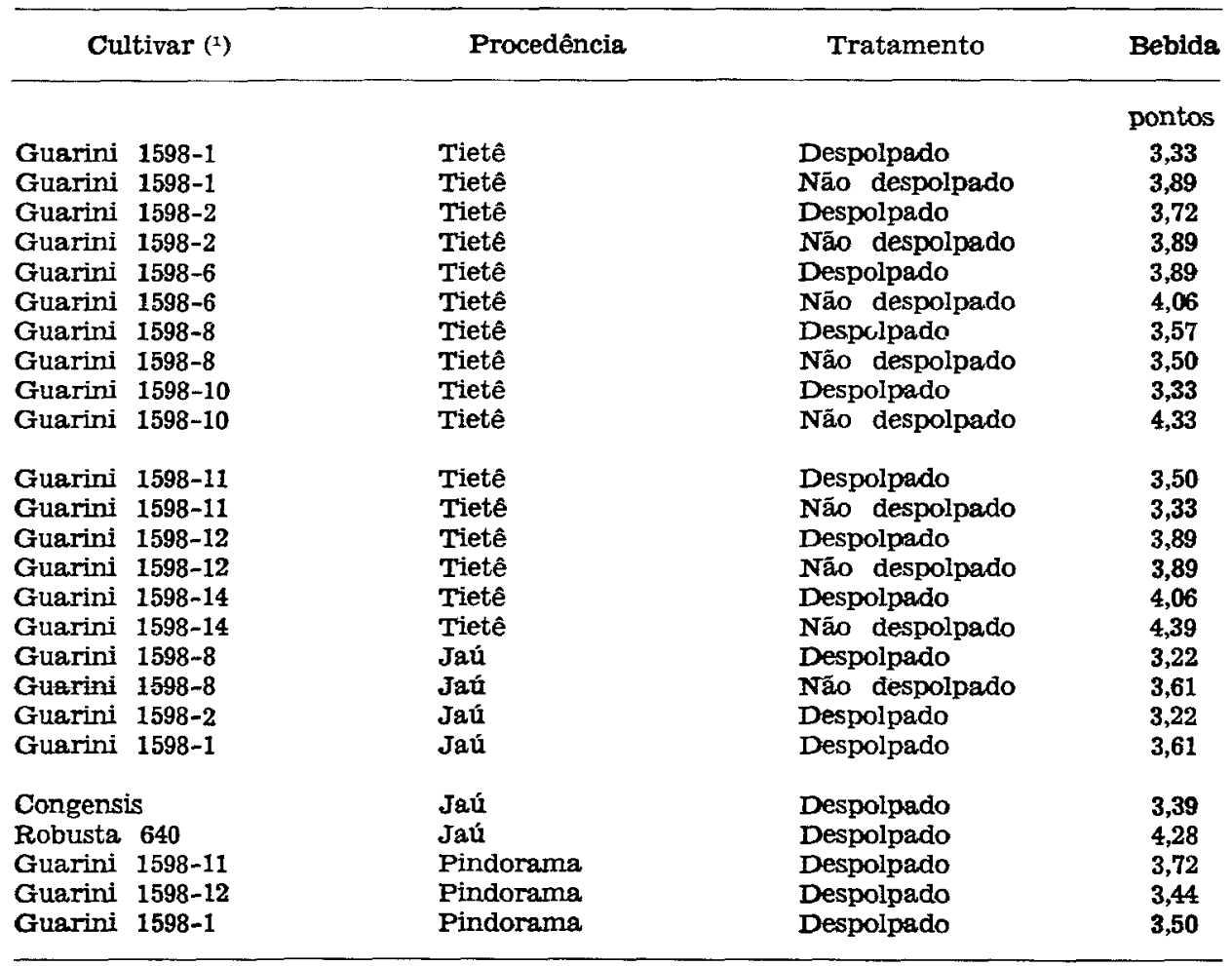


QUADRO 2. - Continuação

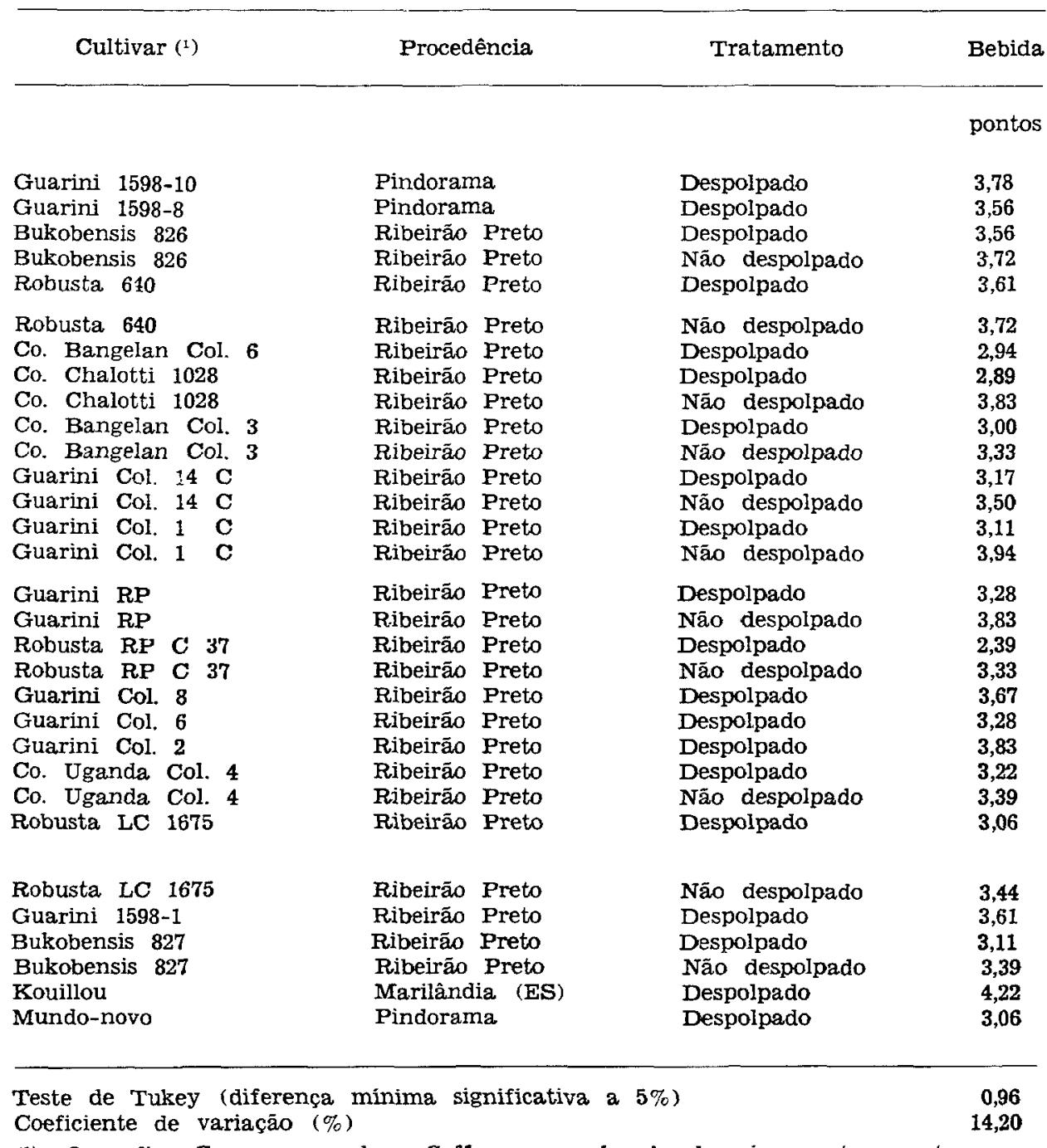

( ${ }^{1}$ O prefixo $\mathrm{Co}$. corresponde a Coffea congensis. As demais amostras pertencem a C. canephora.

As médias dos pontos variaram de 2,39, conferido à amostra do cultivar robusta RP C 37, despolpada, com melhor bebida, a 4,39 , de guarini 1598-14 de Tietê, amostra sem despolpamento. O cultivar testemu- nha mundo-novo deu média de 3,06 pontos, enquanto o kouillou deu 4,22 pontos.

O ensaio foi primeiramente analisado de acordo com o delineamento 
reticulado retangular. Devido à baixa eficiência $(4,6 \%)$ desse tipo de delineamento, em relação ao de bloco ao acaso, optou-se pela análise neste delineamento. A análise estatística das médias obtidas para a qualidade da bebida revelou, pelo teste $\mathrm{F}$, a $1 \%$, a existência de diferenças significativas entre os tratamentos. $\mathrm{O}$ valor do coeficiente de variação foi de $14,2 \%$ e o valor da diferença mínima significativa, para contrastes de médias, pelo teste de Tukey a 5\%, foi de 0,96 ponto. Foi possível identificar 20 tratamentos que tiveram melhor bebida e não diferiram do ponto de vista estatístico. Em relação à melhor qualidade da bebida, sobressaíram-se os cafés dos cultivares robusta RP C 37 , LC 1675, guarini col. 1 e bukobensis 827 de C. canephora e bangelan coleções 6 e 3 e chalotti LC 1028 de $\mathbf{C}$. congensis, todos cafés despolpados e de Ribeirão Preto, e o despolpado mundo-novo de Pindorama (quadro 2).

As 17 amostras despolpadas dos cultivares de C. canephora deram média de 3,40 pontos, enquanto as 17 correspondentes e não despolpadas deram média de 3,75 , havendo diferenças significativas entre elas, pelo teste F a $1 \%$. Uma análise por localidade conduziu a resultados semelhantes: encontraram-se, para as médias das oito amostras de Tietê e para as oito de Ribeirão Preto, valores significativos de F. As'três amostras de café da espécie C. congensis de Ribeirão Preto deram médias de 3,04 e 3,52 pontos, respectivamente para café despolpado e não despolpado. $O$ contraste entre essas médias revelou-se significativo ( $\mathrm{F}$ a $1 \%$ ). Não levando em conta o tratamento, isto é, com ou sem despolpamento, as amostras de C. congensis deram 3,28 pon- tos e, as de C. canephora, 3,50. Considerando apenas as amostras de $\mathbf{C}$. canephora provenientes de café despolpado, por localidade, verificou-se que aquelas de Tietê tiveram média de 3,66 (8 amostras), enquanto as de Jaú (4 amostras), Pindorama (5 amostras) e Ribeirão Preto (12 amostras) tiveram médias de $3,58,3,60 \mathrm{e}$ 3,27 respectivamente. Apenas deram significativos os contrastes feitos entre as médias de Ribeirão Preto e as das três outras localidades ( $F$ a 1\%).

Comparações pelo teste de Tukey a $5 \%$ dos tratamentos com as testemunhas kouillou e mundo-novo, conduziram a contrastes significativos. Apenas oito das amostras analisadas têm, por esse teste, bebida melhor do que o cultivar kouillou, e nenhuma se revelou melhor do que a do padrão mundo-novo. Todavia, muitas amostras de $\mathbf{C}$. canephora e $\mathbf{C}$. congensis deram bebida semelhante a esse padrão.

\section{DISCUSSÃO E CONCLUSÃO}

No presente trabalho usaram-se padrōes específicos de bebida para C. canephora $(2,7)$, com uma escala de cinco pontos, em virtude de não ter sido favorável $(\mathbf{5}, \mathbf{6 )}$ o emprego de padrões de bebida utilizados para C. arabica, no sentido de avaliar a qualidade da bebida do café das espécies $C$. canephora e $C$. congensis.

A amostra padrão de sementes de C. canephora, correspondente ao cultivar kouillou, apresentou, além de sementes pequenas e película aderente marrom, bebida inferior, com média de 4,22 pontos. Os peritos que classificaram as amostras acham-se mais familiarizados com C. arabica e, pou- 
cas vezes, tiveram oportunidade de classificar café dos cultivares de $\mathbf{C}$. canephora e $\mathbf{C}$. congensis de várias procedências, como no experimento. Apesar de os classificadores não terem conhecimento de qual amostra representava o padrão, a existência de amostras com sementes pequenas e aspecto desfavorável talvez os tenha levado a considerar aquelas com sementes maiores e de película menos aderente, como semelhantes às de $\mathbf{C}$. arahica, cuja variação lhes é bem conhecida. Daí o motivo de $46 \%$ das amostras examinadas, tanto de $\mathbf{C}$. canephora como de $\boldsymbol{C}$. congensis terem sido classificadas como de $\boldsymbol{C}$. arabica, independentemente de serem ou não despolpadas. Apenas $36 \%$ das amostras examinadas foram classificadas como de $\mathbf{C}$. canephora.

E de interesse notar que em cinco amostras de $C$. canephora a quantidade de sementes do tipo moca, tão comumente encontrada nesse café, foi menor do que na amostra-padrão de C. arabica. A quantidade mais reduzida desse tipo de sementes, de $5 \%$ apenas, foi encontrada na amostra de C. canephora 1675, de Ribeirão Preto. Essa baixa porcentagem de sementes moca poderia estar relacionada com a autofertilidade desse cafeeiro. Novas observaçōes serão realizadas para verificar essa possibilidade. Também essas porcentagens reduzidas de sementes moca podem estar relacionadas com fatores do ambiente, como já foi salientado, para amostras de sementes de C. arabica, colhidas em anos diferentes (1).

Os 20 tratamentos de melhor bebida (menores médias de pontos), correspondem, de acordo com a procedência das amostras, a três de Tietê, três de Jaú, 13 de Ribeirão
Preto e uma de Pindorama (C. arabica). Convém, ainda, assinalar que além da amostra do cultivar mundonovo, nove são do cultivar guarini, quatro de robusta e seis de cultivares de $\mathbf{C}$. congensis, indicando que tanto a espécie $\mathbf{C}$. congensis como a $\mathbf{C}$. canephora podem dar bebida semelhante. Além disso, nota-se que desses 20 tratamentos, 17 correspondem a amostras de café despolpado e, apenas três, a de não despolpado. Quando se examinaram as 17 amostras das mesmas plantas, cujos frutos maduros foram despolpados ou foram secos sem despolpar, verificou-se que as amostras não despolpadas deram 3,75 pontos, em média, enquanto as despolpadas tiveram média de 3,40 pontos. Essa diferença, pelo teste $\mathrm{F}$ a $1 \%$, mostrou-se significativa.

As médias dos pontos conferidos às amostras despolpadas de $\mathbf{C}$. canephora para Tietê, Jaú, Pindorama e Ribeirão Preto, foram de 3,66, 3,58, 3,60 e 3,27 respectivamente. Diferenças significativas foram reveladas na comparação da média de Ribeirão Preto com as demais localidades.

É provável que a espécie $\mathbf{C}$. canephora não venha a ser cultivada em larga escala no planalto paulista, região tradicionalmente de $\mathbf{C}$. arabica. Os dados do presente experimento mostram que nessa regiāo, com inverno seco e frio, os cultivares examinados de C. canephora, despolpados, dão bebida melhor do que os não despolpados, confirmando resultados anteriormente obtidos em Angola (2). Para o litoral paulista, com condições favoráveis a $\mathbf{C}$. canephora e desfavoráveis à qualidade da bebida, a prática do despolpamento seria, ainda, mais recomendável. Caso, porém, o Estado de São Paulo venha a cultivar 
essa espécie ou C. congensis, os dados indicam que alguns cultivares, com melhor qualidade de bebida, poderiam ser indicados para plantio, se tiverem, aliada a essa característica, a boa produtividade.

\section{CUP QUALITY EVALUATION OF COFFEA CANEPHORA AND COFFEA CONGENSIS COLTIVARS}

\section{SUMMARY}

Coffea canephora and C. congensis cultivars were evaluated for morphological and cup quality characteristics, comparing seed samples from four localities of the State of Sāo Paulo. A five point scale, developed in Angola for testing cup quality of C. canephora, was used. C. canephora cv. Kouillou, from the State of Espirito Santo, and $C$. arabica cv. Mundo-Novo were used as standards.

According to morphological characteristics $46 \%$ of the clean coffee samples were classified as C. arabica and $36 \%$ as C. canephora. The percentage of peaberries varied from 10 to $50 \%$ for $\mathbf{C}$. canephora and from 20 to $40 \%$ for C. congensis, while Mundo-Novo gave $15 \%$ of this seed type.

In relation to the cup quality eight samples proved to be significantly better than Kouillou. However none of the samples showed to be better than Mundo-Novo. A positive and significant effect of pulping on cup quality was observed when comparing 17 pulped coffee samples to the corresponding samples without pulping. Furthermore an effect of locality on cup quality was observed. The best cup quality was obtained from the pulped coffee samples of Ribeirão Preto locality.

The analysed results pointed also out that $\mathbf{C}$. canephora and $\mathbf{C}$. congensis cultivars can give beverages of similar cup quality.

\section{LITERATURA CITADA}

1. CARVAlHo, A.; MONACO, L. C. \& FAzUOLI, L. C. Melhoramento do cafeeiro. XXXIX - Produtividade e características de progênies $S_{2}$ e $S_{3}$ de Mundo-Novo e Bourbon Amarelo e de hibridos entre esses cultivares. Bragantia, Campinas, $37: 129-138,1978$.

2. CORTE DOS SANTOS, A.; LOPES, F.; ROCHA LIMA, A. \& NOGUEIRA, C. Tecnologia de campo no café robusta. Resultados preliminares. Luanda, Instituto do Café de Angola, Departamento de Estudos Tecnológicos, 1967. 27p.

3. GARRUTTI, R. S.; CARVALHO, A. \& TOSELLO, Y. Qualidade da bebida em blends de cafés arábica e robusta. In: Congresso Brasileiro de Pesquisas Cafeeiras, 3., Curitiba, 1975. Resumos. Rio de Janeiro, Instituto Brasileiro do Café, 1975. p.33.

4. TEIXEIRA, A. A. A técnica experimental de degustação do café. Piracicaba, ESALQ, USP, 1972. 99p. (Tese de doutoramento)

5. F F FuzUli, L. C.; CARvalho, A. \& MONACO, L. C. Avaliação da bebida de algumas espécies de híbridas interespecíficos de coffea Ciência e Cultura, São Paulo, Supl. 26(7) 565, 1974.

6. __ _ _ _ _ _ _ _ _ Q Q hibridos de Coffea. Ciência e Cultura, São Paulo, Supl. 24(6):402-403, 1972.

7. XABREGaS, J.; MEXIA, J. R.; GONCALVES, A.; CORTE DOS SANTOS, A.; GOMES, V. \& NOGUEIRA, C. Análise de algumas características dos cafés verdes de Angola. Luanda, Instituto do Café de Angola, Departamento de Estudos Tecnológicos, 1971. 79p. (Bol. 3) 